\title{
Therapeutic effect of vitamin K1 combined with meropenem on the treatment of pertussis syndrome
}

\author{
${\text { WENXIN } \mathrm{CHEN}^{1} \text { and YUFENG GUO }}^{2}$ \\ Departments of ${ }^{1}$ Pediatric Internal Medicine and ${ }^{2}$ Cardiothoracic Surgery, \\ The Second People's Hospital of Liaocheng, Liaocheng, Shandong 252600, P.R. China
}

Received December 4, 2018; Accepted April 19, 2019

DOI: $10.3892 /$ etm.2019.7586

\begin{abstract}
Clinical efficacy of vitamin K1 combined with meropenem on the treatment of pertussis syndrome was evaluated. Clinical data of 170 children with pertussis syndrome treated in the Second People's Hospital of Liaocheng from March 2015 to March 2017 were collected. Of these, 87 patients who were treated with vitamin K1 combined with meropenem were regarded as the experiment group. A total of 83 patients who were treated with meropenem alone were regarded as the control group. Both groups were treated with anti-infective, respiratory support, antispasmodic, expectorant and other basic treatments. The therapeutic effects, duration of spasmodic cough, length of hospitalization, antipyretic time, duration of voice disappearance and healing time were observed between the two groups. The duration of spasmodic cough and length of hospitalization in the experiment were lower than the control group, and the difference was statistically significant between the groups $(\mathrm{P}<0.05)$. The explicit efficiency $(51.72 \%)$ and total effective efficiency $(99.55 \%)$ in the experiment group were significantly higher than the explicit efficiency (36.14\%) and total effective efficiency $(78.31 \%)$ in the control group. There was a statistically significant difference between the groups $(\mathrm{P}<0.05)$. The voice disappearance time and healing time in the experiment group were significantly shorter than the control group, and there was a statistically significant difference between the groups $(\mathrm{P}<0.05)$. The antipyretic time in the experiment group was lower than that of the control group, the difference between the groups was not statistically significant $(\mathrm{P}>0.05)$. The treatment with vitamin K1 and meropenem has a significant effect in relieving pediatric pertussis syndrome, it can shorten the duration of spasmodic cough, antipyretic time, duration of voice disappearance and length of hospitalization
\end{abstract}

Correspondence to: Dr Wenxin Chen, Department of Pediatric Internal Medicine, The Second People's Hospital of Liaocheng, 1 Huamei Road, Liaocheng, Shandong 252600, P.R. China E-mail: c9x74f@163.com

Key words: vitamin K1, meropenem, pertussis syndrome, clinical efficacy in children with pertussis syndrome, and improve the efficacy clinically.

\section{Introduction}

Pertussis syndrome is also known as day-cough syndrome, and is very difficult to distinguish from pertussis. The typical clinical manifestations of pertussis syndrome are characterized by paroxysmal cough, cough with choking echo and peripheral blood lymphocytosis. However, the clinical performance of infants less than 6 months is not typical. Most of them have suffocation with slow heartbeat, difficult breathing while coughing, as the main symptoms $(1,2)$ due to blockage of organ secretions caused by hypoxia and suffocation. This disease has a long course of illness with a complicated medical history, and severe life-threatening illness (3). It has been reported that paroxysmal cough in pertussis children within 6 months only accounted for $10 \%$, and respiration stopped after coughing accounted for $18 \%$ (4). Findings have shown that pertussis syndrome is associated with adenovirus (5). According to the statistics of the World Health Organization in recent years, even under the high coverage of diphtheria-pertussis-tetanus combined vaccine, the incidence of pertussis is still on the increase with a small margin (6). According to reports of the American Prevention Center, in 2012, the incidence of pertussis has reached its 50-year highest level (7). The current equipment used to identify the two diseases is expensive and many hospitals have not yet been popularized (8).

Vitamin $\mathrm{K}$ is a fat-soluble vitamin, used for unique post-translational chemical modification of proteins with calcium-binding properties. These proteins are collectively referred to as vitamin K-dependent proteins (VKDPs) or Gla proteins. Vitamin $\mathrm{K}$ is mainly used for coagulation, but it is also involved in the metabolic pathways of bones and other tissues $(9,10)$. Vitamin $\mathrm{K}$ contains vitamin $\mathrm{K} 1$ and vitamin K2 (11). Previous findings have shown that vitamin $\mathrm{K} 1$ has a contractile effect against acetylcholine and smooth muscle, and has a sedative effect on central nervous organs $(12,13)$. In addition, vitamin K1 exerts an antitussive effect on bronchiolitis and bronchial asthma (14). In the 1930s, Per et al reported that the extract of alfalfa ether can be used for hemostasis, separate the yellow oil from the alfalfa, and named it as vitamin K1 (15). Meropenem is a second-generation carbapenem antibiotic. Compared to the first-generation, 
Table I. Comparison of general information between the groups of patients [n (\%)].

\begin{tabular}{|c|c|c|c|c|}
\hline Groups & The experiment group $(\mathrm{n}=87)$ & The control group $(\mathrm{n}=83)$ & $\chi^{2}$ & P-value \\
\hline \multicolumn{5}{|l|}{ Sex } \\
\hline Male & $39(44.83)$ & $42(50.60)$ & \multirow[t]{2}{*}{0.568} & \multirow[t]{2}{*}{0.451} \\
\hline Female & $48(55.17)$ & $41(49.40)$ & & \\
\hline \multicolumn{5}{|l|}{ Age (years) } \\
\hline$<6$ & $35(40.23)$ & $38(45.78)$ & \multirow[t]{2}{*}{0.535} & \multirow[t]{2}{*}{0.465} \\
\hline$\geq 6$ & $52(59.77)$ & $45(54.22)$ & & \\
\hline \multicolumn{5}{|l|}{ Weight (kg) } \\
\hline$<15$ & $37(42.53)$ & $40(48.19)$ & \multirow[t]{2}{*}{0.550} & \multirow[t]{2}{*}{0.458} \\
\hline$\geq 15$ & $50(57.47)$ & $43(51.81)$ & & \\
\hline \multicolumn{5}{|l|}{ Height (m) } \\
\hline$<1$ & $41(47.13)$ & $39(46.99)$ & \multirow[t]{2}{*}{0.001} & \multirow[t]{2}{*}{0.986} \\
\hline$\geq 1$ & $46(52.87)$ & $44(53.01)$ & & \\
\hline \multicolumn{5}{|c|}{ Fecal routine } \\
\hline Normal & $40(45.98)$ & $40(48.19)$ & \multirow[t]{2}{*}{0.084} & \multirow[t]{2}{*}{0.772} \\
\hline Abnormal & $47(54.02)$ & $43(51.81)$ & & \\
\hline \multicolumn{5}{|l|}{ Vomiting } \\
\hline Yes & $42(48.28)$ & $41(49.40)$ & \multirow[t]{2}{*}{0.021} & \multirow[t]{2}{*}{0.884} \\
\hline No & $45(51.72)$ & $42(50.60)$ & & \\
\hline \multicolumn{5}{|l|}{ Crying } \\
\hline Yes & $35(40.23)$ & $32(38.55)$ & \multirow[t]{2}{*}{0.050} & \multirow[t]{2}{*}{0.823} \\
\hline No & $52(59.77)$ & $51(61.45)$ & & \\
\hline \multicolumn{5}{|c|}{ Loss of appetite } \\
\hline Yes & $46(52.87)$ & $44(53.01)$ & \multirow[t]{2}{*}{0.001} & \multirow[t]{2}{*}{0.986} \\
\hline No & $41(47.13)$ & 39 (46.99) & & \\
\hline
\end{tabular}

the second-generation has a higher safety and a stronger antibacterial effect on Gram-negative bacteria $(16,17)$. The current study focused on the clinical analysis of meropenem in the treatment of pertussis syndrome with vitamin $\mathrm{K} 1$.

\section{Patients and methods}

General information. A total of 170 children with pertussis syndrome in The Second People's Hospital of Liaocheng (Liaocheng, China) from March 2015 to March 2017 were collected. Of these, 83 patients were treated with vitamin K combined with meropenem and regarded as the experiment group. A total of 87 patients were treated with meropenem alone and were regarded as the control group. The experiment group included 39 males and 48 females, with an average age of $7.54 \pm 1.84$ years. The control group included 42 males and 41 females, with an average age of $8.04 \pm 1.51$ years. Both groups were treated with anti-infective, antispasmodic, expectorant and other basic treatments. Informed consent was obtained from the family members of each research subject.

Inclusion criteria: i) the patients had no drug contraindications; and ii) patients who insisted on the treatment for $>3$ days

Exclusion criteria: i) patients with severe malnutrition, digestive diseases, congenital heart disease and respiratory disease; and ii) patients with moderate dehydration, hypovolemic shock or other critical illnesses.

The study was approved by the Ethics Committee of The Second People's Hospital of Liaocheng. Patients who participated in this research had complete clinical data. Signed informed consent was obtained from the parents of the child patients.

Drugs. The drugs used were: Vitamin K1 injection [Shanghai Modern Hasen (Shangqiu) Pharmaceutical Co., Ltd., Shanghai, China], specification $1 \mathrm{ml}: 10 \mathrm{mg}$, Chinese medicine quasi-word H20044180. Injection of meropenem (ShenzhenHaibin Pharmaceutical Co., Ltd., Shenzhen, China), $0.5 \mathrm{gx} 1$ bottle/box, national medicine quasi-word H20010250.

Methods of administration. In the control group, $1.0 \mathrm{~g}$ of meropenem was added to $100 \mathrm{ml}$ of $0.9 \%$ sodium chloride injection, intravenous drip, 3 times per day. In the experiment group, patients were given vitamin K1 intramuscular injection on the basis of the control group, twice per day and only given $10 \mathrm{mg} /$ time for patients aged under 1 year, and 15-20 mg/time for patients aged over 1 year. There were 6 days in one course of treatment. Each patient was treated with 2 courses of treatment, and the clinical treatment effect was observed after 2 courses of treatment. 
Table II. Comparison of clinical efficacy between the groups of patients [n (\%)].

\begin{tabular}{lcccc}
\hline Groups & Significantly-effective & Effective & Non-effective & Total effective rate \\
\hline Experiment group $(\mathrm{n}=87)$ & $45(51.72)$ & $39(44.83)$ & $3(3.45)$ & $84(96.55)$ \\
Control group $(\mathrm{n}=83)$ & $30(36.14)$ & $35(42.17)$ & $18(21.69)$ & $65(78.31)$ \\
$\chi^{2}$ & 4.182 & 0.122 & 13.05 & 11.98 \\
P-value & 0.040 & 0.727 & 0.001 & 0.001 \\
\hline
\end{tabular}

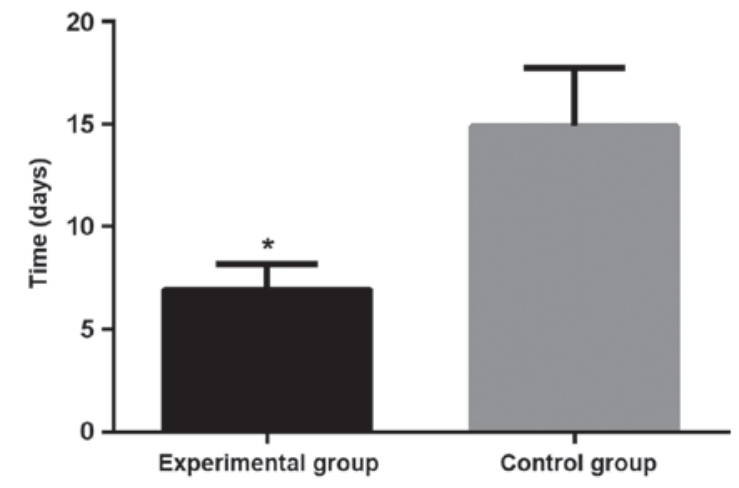

Figure 1. Comparison of duration of spastic cough between the experiment and the control groups. The duration of spasmodic cough in the experiment group was significantly lower than the control group, the difference between the groups was statistically significant $\left({ }^{*} \mathrm{P}<0.05\right)$.

Observation and judgment of indices. Efficacy judgment: after 5 days of treatment, cough $<8$ times, was classified as significantly-effective; after 7 days of treatment, cough $<4$ time, was classified as effective. After taking the drug for 1 week, if there is no obvious improvement or the condition became aggravated, the drug was replaced and classified non-effective. Effectiveness $=($ significantly - effective + effective $) /$ total number x $100 \%$.

Statistical analysis. Statistical analysis was performed on the research data using SPSS 17.0 (Beijing Bo Yi Zhi Xun Information Technology Co., Ltd., Beijing, China) statistical software. Measurement data were expressed in terms of the mean \pm standard deviation, t-test was used. Counting data were expressed in percentages $(\%)$. The $\chi^{2}$ test was used for comparisons of two graphs. $\mathrm{P}<0.05$ was considered to indicate a statistically significant difference.

\section{Results}

Comparison of general information. There were no significant differences in terms of sex, age, height, weight, heat, vomiting, stomach ache, fecal routine, crying, and loss of appetite between the groups of patients with pertussis syndrome (P>0.05; Table I).

\section{Clinical efficacy}

Comparison of duration of spasmodic cough and length of hospitalization between the groups. The duration of spasmodic cough and length of hospitalization in the experiment group was $6.94 \pm 1.27$ and $8.97 \pm 1.79$ days, respectively. The

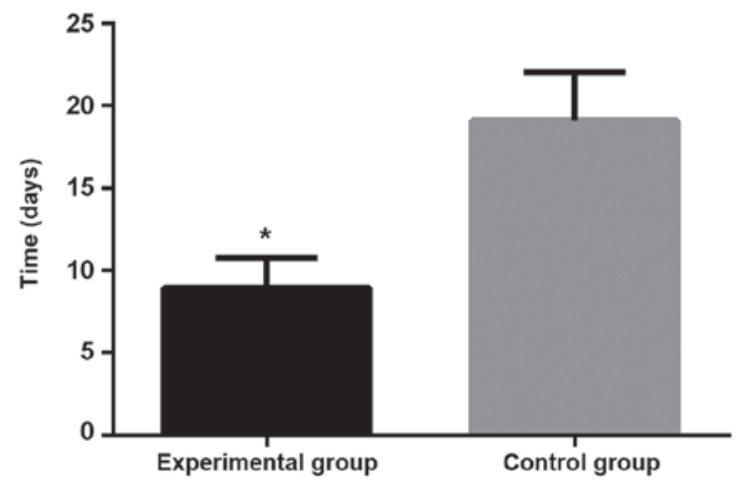

Figure 2. Comparison of length of hospitalization between the experiment and the control groups. The length of hospitalization in the experiment group was lower than the control group, the difference between the groups was statistically significant ( $\mathrm{P}<0.05)$.

duration of spasmodic cough and length of hospitalization in the control group was $14.91 \pm 2.81$ and $19.11 \pm 2.89$ days, respectively. The duration of spasmodic cough in the experiment group was lower than the control group, the difference between the groups was statistically significant $(\mathrm{P}<0.05)$. The length of hospitalization in the experiment group was lower than the control group, the difference between the groups was statistically significant $(\mathrm{P}<0.05$; Figs. 1 and 2$)$.

Clinical efficacy between the groups of patients. In the experiment group, there were 45 cases of significantly-effective patients, 39 cases of effective patients, and 3 cases of non-effective patients, the total effective rate was $96.55 \%$. In the control group, there were 30 cases of significantly-effective patients, 35 cases of effective patients and 18 cases of non-effective patients, the total effective rate was $78.31 \%$. The total effective rate in the experiment group was significantly higher than the control group, and the difference was statistically significant $(\mathrm{P}<0.05$; Table II).

Comparison among antipyretic time, duration of voice disappearance and healing time. The antipyretic time, duration of voice disappearance and healing time in the experiment group were $1.78 \pm 0.61,6.01 \pm 0.75$ and $6.81 \pm 1.32$ days, respectively. The antipyretic time, duration of voice disappearance and healing time in the control group were 2.04 \pm 0.94 , $13.54 \pm 1.84$ and $19.44 \pm 2.74$ days, respectively. The duration of voice disappearance and healing time in the experiment group were significantly lower than the control group, the difference between the groups was statistically significant $(\mathrm{P}<0.05)$. The antipyretic time in the experiment group was lower than the control group, and the difference between the groups was not statistically significant ( $\mathrm{P}>0.05$; Table III). 
Table III. Comparison of antipyretic time, duration of voice disappearance and healing time between the groups (mean \pm standard deviation).

\begin{tabular}{lccr}
\hline Groups & Antipyretic time (days) & Duration of voice disappearance (days) & Healing time (days) \\
\hline Experiment group $(\mathrm{n}=87)$ & $1.78 \pm 0.61$ & $6.01 \pm 0.75$ & $6.81 \pm 1.32$ \\
Control group $(\mathrm{n}=83)$ & $2.04 \pm 0.94$ & $13.54 \pm 1.84$ & $19.44 \pm 2.74$ \\
$\mathrm{t}$ & 0.137 & 35.23 & 38.56 \\
P-value & 1.494 & $<0.001$ & $<0.001$ \\
\hline
\end{tabular}

\section{Discussion}

Pertussis syndrome is a common lower respiratory tract infectious disease in infants. According to statistics, approximately 300,000 children die each year due to pertussis syndrome. Particularly, the disease condition had become more severe in small infants $(18,19)$. The disease progressed rapidly in the absence of protective antibodies in 3 months old infants. If combined with cardiovascular dysfunction, the difficulty of treatment will increase (20). Due to the slender trachea in children lung secretions cannot be effectively discharged, this leads to intracellular bacterial growth in the tracheal ciliated skin, blocked cilia movement and affects excretion discharge. Large accumulation of inflammatory secretions in the trachea stimulate the nerve endings and cause severe paralysis $(21,22)$. Some reports indicate that respiratory syncytial virus and bordetella parapertussis were the main causes of pediatric pertussis syndrome $(23,24)$. In this investigation, depending on the treatment method, patients were divided into two different groups. Among them, 87 patients in the experiment group were treated with vitamin K1 combined with meropenem. A total of 83 patients in the control group were treated with meropenem alone. The general information between the groups was compared, the results showed that the general information difference was not statistically significant $(\mathrm{P}>0.05)$, suggesting that the groups of patients had comparability. First, we compared the duration of spasmodic cough and the length of hospitalization between the groups, the results showed that the duration of spasmodic cough in the experiment group was significantly lower than the control group, and the difference between the groups was statistically significant $(\mathrm{P}<0.05)$. The length of hospitalization in the experiment group was significantly shorter than the control group, the difference between the groups was statistically significant $(\mathrm{P}<0.05)$. This suggested that vitamin $\mathrm{K} 1$ combined with meropenem can shorten the duration of spasmodic cough and length of hospitalization. Recent research has shown that vitamin $\mathrm{K} 1$ can relieve spasmodic cough in patients as well as reduce the cough duration and length of hospitalization (25). This is consistent with our results. Clinically, vitamin K1, as an effective drug for the treatment of pertussis, can alleviate spasmodic cough. It is speculated that vitamin K1 promoted the synthesis of prothrombin in the liver to achieve the effect of hemostasis, and reduced the number of complications caused by spasmodic cough in order to shorten the disease duration. Then, the clinical efficacy was compared between the groups of patients. The results showed that, the experiment group, included 45 cases of significantly-effective patients, 39 cases of effective patients and 3 cases of non-effective patients, and the total effective rate was $96.55 \%$. The control group, included 30 cases of significantly-effective patients, 35 cases of effective patients and 18 cases of non-effective patients, with a total effective rate of $78.31 \%$. The total effective rate in the experiment group $(96.55 \%)$ was significantly higher than the control group (78.31\%), the difference was statistically significant $(\mathrm{P}<0.05)$. It is suggested that the clinical efficacy of vitamin $\mathrm{K} 1$ combined with meropenem in the treatment of spasmodic cough is better than the clinical efficacy of meropenem alone. Currently, there is no relevant report on the efficacy between the groups. Meropenem, a type of carbapenem antibiotic, has broad-spectrum activity and is widely used for antibacterial treatment of infections in the respiratory tract, urinary tract and digestive tract (26). Our results suggested that, meropenem during the period of antibacterial and anti-infection, adding appropriate amount of vitamin K1 can supplement the body's vitamin K1 deficiency to prevent respiratory hemorrhage, so that combining both drugs can achieve a better efficacy. Next, the antipyretic time, duration of voice disappearance and healing time were compared. The results showed that the duration of voice disappearance and healing time in the experiment group were significantly lower than the control group, the difference between the groups was statistically significant $(\mathrm{P}<0.05)$. The antipyretic time in the experiment group was lower than the control group, the difference between both groups was not statistically significant $(\mathrm{P}<0.05)$. It is suggested that vitamin $\mathrm{K} 1$ combined with meropenem can help to shorten the duration of voice disappearance and healing time, which is more conducive to the rehabilitation of spasmodic cough. Currently, no relevant reports exist. From the pathological point of view, there may be respiratory secretion elimination disorder caused by respiratory inflammation, however, meropenem has an excellent antibacterial and anti-inflammatory effect and vitamin $\mathrm{K} 1$ has a good hepatic coagulation function. The drugs combined achieve the best possible effect.

There are only a small number of patients in this study, which is not a sufficiently adequate data analysis, therefore, certain limitations may exist. There is currently very little scientific research on the drugs between the groups, so we will continue to conduct relative research and improve the accuracy of the results.

In summary, treatment of meropenem combined with vitamin K1 has a significant effect on relieving children with spasmodic cough syndrome. It can shorten the duration of spasmodic cough, length of hospitalization antipyretic time and duration of voice disappearance as well as improve the 
clinical efficacy. We also emphasize that timely vaccination is the key to preventing spasmodic cough, even if the patient suffers from spasmodic cough, the disease condition would be much milder.

\section{Acknowledgements}

Not applicable.

\section{Funding}

No funding was received.

\section{Availability of data and materials}

The datasets used and/or analyzed during the present study are available from the corresponding author on reasonable request.

\section{Authors' contributions}

WC and YG analyzed and interpreted the patient data, performed the experiments and designed the study, and were responsible for the analysis and discussion of the data and designed the methods. WC wrote the manuscript. WC and YG read and approved the final manuscript.

\section{Ethics approval and consent to participate}

The study was approved by the Ethics Committee of The Second People's Hospital of Liaocheng (Liaocheng, China). Patients who participated in this research had complete clinical data. Signed informed consents were obtained from the parents of the child patients.

\section{Patient consent for publication}

Not applicable.

\section{Competing interests}

The authors declare that they have no competing interests.

\section{References}

1. Ferronato AE, Gilio AE and Vieira SE: Respiratory viral infections in infants with clinically suspected pertussis. J Pediatr (Rio J) 89: 549-553, 2013.

2. Burr JS, Jenkins TL, Harrison R, Meert K, Anand KJ, Berger JT, Zimmerman J, Carcillo J, Dean JM, Newth CJ, et al; Eunice Kennedy Shriver National Institute of Child Health and Human Development (NICHD) Collaborative Pediatric Critical Care Research Network (CPCCRN): The Collaborative Pediatric Critical Care Research Network Critical Pertussis Study: collaborative research in pediatric critical care medicine. Pediatr Crit Care Med 12: 387-392, 2011.

3. Craig-Mylius KA and Weiss AA: Antibacterial agents and release of periplasmic pertussis toxin from Bordetella pertussis. Antimicrob Agents Chemother 44: 1383-1386, 2000.

4. Hozbor D, Mooi F, Flores D, Weltman G, Bottero D, Fossati S, Lara C, Gaillard ME, Pianciola L, Zurita E, et al: Pertussis epidemiology in Argentina: trends over 2004-2007. J Infect 59: 225-231, 2009.

5. Nelson KE, Gavitt F, Batt MD, Kallick CA, Reddi KT and Levin S: The role of adenoviruses in the pertussis syndrome. J Pediatr 86: 335-341, 1975.
6. Guiso N, Wirsing von König $\mathrm{CH}$, Forsyth $\mathrm{K}$, Tan $\mathrm{T}$ and Plotkin SA: The Global Pertussis Initiative: report from a round table meeting to discuss the epidemiology and detection of pertussis, Paris, France, 11-12 January 2010. Vaccine 29: 1115-1121, 2011.

7. Cherry JD: Epidemic pertussis in 2012 - the resurgence of a vaccine-preventable disease. N Engl J Med 367: 785-787, 2012.

8. Salimi A, Eybagi S, Seydi E, Naserzadeh P, Kazerouni NP and Pourahmad J: Toxicity of macrolide antibiotics on isolated heart mitochondria: a justification for their cardiotoxic adverse effect. Xenobiotica 46: 82-93, 2016.

9. Shearer MJ: Vitamin K. Lancet 345: 229-234, 1995.

10. Shearer MJ: Role of vitamin K and Gla proteins in the pathophysiology of osteoporosis and vascular calcification. Curr Opin Clin Nutr Metab Care 3: 433-438, 2000.

11. De Caterina R, Husted S, Wallentin L, Andreotti F, Arnesen H, Bachmann F, Baigent C, Huber K, Jespersen J, Kristensen SD, et al: Vitamin $\mathrm{K}$ antagonists in heart disease: Current status and perspectives (Section III). Position paper of the ESC Working Group on Thrombosis-Task force on anticoagulants in heart disease. Thromb Haemost 110: 1087-1107, 2013.

12. Wang Y: New materia medica project: synthetic biology based bioactive metabolites research in medicinal plant. Sheng Wu Gong Cheng Xue Bao 33: 478-485, 2017 (In Chinese).

13. Koklu E, Taskale T, Koklu S and Ariguloglu EA: Anaphylactic shock due to vitamin $\mathrm{K}$ in a newborn and review of literature. J Matern Fetal Neonatal Med 27: 1180-1181, 2014.

14. Nowak-Göttl U, Dietrich K, Schaffranek D, Eldin NS, Yasui Y, Geisen C and Mitchell LG: In pediatric patients, age has more impact on dosing of vitamin $\mathrm{K}$ antagonists than VKORC1 or CYP2C9 genotypes. Blood 116: 6101-6105, 2010.

15. Per H, Arslan D, Gümüs $H$, Coskun A and Kumandas S: Intracranial hemorrhages and late hemorrhagic disease associated cholestatic liver disease. Neurol Sci 34: 51-56, 2013.

16. Rhomberg PR and Jones RN; MYSTIC Program (USA) Study Group: Antimicrobial spectrum of activity for meropenem and nine broad spectrum antimicrobials: report from the MYSTIC Program (2002) in North America. Diagn Microbiol Infect Dis 47: 365-372, 2003.

17. Abo El Sooud K: Plasma pharmacokinetics and urine concentrations of meropenem in ewes. J Vet Pharmacol Ther 27: 27-30, 2004.

18. Forsyth KD, Wirsing von Konig $\mathrm{CH}$, Tan T, Caro J and Plotkin S: Prevention of pertussis: recommendations derived from the second Global Pertussis Initiative roundtable meeting. Vaccine 25: 2634-2642, 2007.

19. Black RE, Morris SS and Bryce J: Where and why are 10 million children dying every year? Lancet 361: 2226-2234, 2003.

20. Tan TQ and Gerbie MV: Pertussis, a disease whose time has come: What can be done to control the problem? Obstet Gynecol 122: 370-373, 2013.

21. Galdi E and Moscato G: Pertussis in the aetiology of chronic cough in adults. Monaldi Arch Chest Dis 57: 229-230, 2002.

22. Wang J, Yang Y, Li J, Mertsola J, Arvilommi H, Shen X and He Q: Infantile pertussis rediscovered in China. Emerg Infect Dis 8: 859-861, 2002.

23. Centers for Disease Control and Prevention (CDC): Updated recommendations for use of tetanus toxoid, reduced diphtheria toxoid and acellular pertussis (Tdap) vaccine from the Advisory Committee on Immunization Practices, 2010. MMWR Morb Mortal Wkly Rep 60: 13-15, 2011.

24. Horiba K, Nishimura N, Gotoh K, Kawaguchi M, Takeuchi S, Hattori $\mathrm{F}$, Isaji $\mathrm{M}$, Okai $\mathrm{Y}$, Hosono $\mathrm{H}$, Takemoto $\mathrm{K}$, et al: Clinical manifestations of children with microbiologically confirmed pertussis infection and antimicrobial susceptibility of isolated strains in a regional hospital in Japan, 2008-2012. Jpn J Infect Dis 67: 345-348, 2014

25. Benzakour O, Gely A, Lara R and Coronas V: Gas-6 and protein $\mathrm{S}$ : Vitamin K-dependent factors and ligands for the TAM tyrosine kinase receptors family. Med Sci (Paris) 23: 826-833, 2007 (In French).

26. Ateskan U, Mas MR, Yasar M, Deveci S, Babaoglu E, Comert B, Mas NN, Doruk H, Tasci I, Ozkomur ME, et al: Deferoxamine and meropenem combination therapy in experimental acute pancreatitis. Pancreas 27: 247-252, 2003.

This work is licensed under a Creative Commons Attribution-NonCommercial-NoDerivatives 4.0 International (CC BY-NC-ND 4.0) License. 